\title{
Leading Organisations in Turbulent Times: Towards a Different Mental Model
}

\author{
Barney Jordaan
}

\begin{abstract}
Organisations that are able to adapt quickly to changing circumstances in their operating environment have a competitive advantage. This level of "agility" involves more than simply developing new strategies and organisational structures to enable the rapid gathering of relevant information and equally rapid response times. Agility also - if not primarily - requires an ability on the part of people in the organisation to collaborate effectively to improve their decision-making abilities both as far as speed and quality of outcome are concerned. Collaboration involves more than the mere acquisition of a particular skills set, e.g., to listen and communicate effectively, or procedural adeptness. Creating a collaborative working environment requires a climate of trust within the organisation and a mindset that is focused on working with, rather than against others to achieve common organisational goals and objectives. Given the human propensity to compete and the so-called trust deficit prevalent in organisations, trustworthiness on the part of leaders and an ability to instil a culture of collaboration are required. However, a number of human and organisational obstacles would need to be overcome to achieve this.
\end{abstract}

\section{Introduction}

The contemporary business environment is characterised by increasing levels of complexity, turbulence and uncertainty. For organisations to survive and thrive in this environment, they need to become more "agile" or adaptive (Rigby et al. 2016). This is not merely a matter of developing an appropriate strategy and organisational structure, but also of leadership (Doz and Kosonen 2008). Whatever label one attaches to it, at the core of the kind of leadership that is needed to navigate this

B. Jordaan (西)

Management Practice, Vlerick Business School, Ghent, Belgium

University of Stellenbosch Business School, Cape Town, South Africa

e-mail: barney.jordaan@ @lerick.com 
turbulence lies the leader's ability to instil a pre-dominant culture of collaboration both inside the organisation and between the organisation and its key stakeholders (Lash 2012). ${ }^{1}$

Because of our hard-wired tendency towards competition (Nicholson 2003), collaboration appears to run counter to our intuitive responses when we are faced with crises, uncertainty or threats. Moving from competition to collaboration is therefore not merely a matter of acquiring a new skills set or process expertise-important as those are-but primarily a matter of fundamentally changing mental models or mindsets. ${ }^{2}$

For collaboration to work optimally, a change in mindset towards a preference for collaboration is not sufficient: organisational trust ${ }^{3}$ is a key requirement as it is associated with enhanced collaboration and improved information sharing and problem-solving (Lewicki and Tomlinson 2003). As indicated later, establishing and maintaining organisational trust-and therefore collaboration-is entirely dependent on the trustworthiness of the organisation's leadership. ${ }^{4}$

In this contribution, after briefly discussing the need for a change from a competitive to a primarily collaborative organisational culture and the role that trust plays in promoting collaboration, I turn to some of the obstacles and challenges that might stand in the way of achieving a leadership mindset and style that promotes a culture of collaboration. While the focus here is on business, the relevance of the points raised might extend beyond the business world as well.

\section{The Current Business Reality: A "VUCA" World}

The general rule seems to be that the level of consciousness of an organization cannot exceed the level of consciousness of its leader (Laloux 2014). ${ }^{5}$

\footnotetext{
${ }^{1}$ The choice of "pre-dominant" is deliberate: collaboration is not always possible or appropriate. For a nuanced treatment of the benefits and limits of collaboration, see Hansen (2009) Collaboration: How Leaders Avoid the Traps, Build Common Ground, and Reap Big Results. Boston: HBR Press. ${ }^{2}$ Mental models determine the strategic approach one takes to deal with problems or make decisions. This, in turn, drives the tactics and behaviour one employs in pursuit of a solution and, ultimately, determines the outcomes achieved. Van Boven and Thompson (2003). "A Look into the Mind of the Negotiator: Mental Models in Negotiation”. Group Processes \& Intergroup Relations. 6(4): 387-404.

${ }^{3}$ For a discussion of the different levels and dimensions of trust, see Fulmer and Gelfand (2012). "At what level (and in whom) we trust: trust across multiple organizational levels." Journal of Management. 38(4): 1167-1230.

${ }^{4}$ See, on the antecedents of organisational trust, Fulmer and Gelfand (2012). "At what level (and in whom) we trust: trust across multiple organizational levels." Journal of Management. 38(4): 1167-1230; Lewicki and Wiethoff (2000). "Trust, trust development, and trust repair" in Coleman et al. (eds., 2014). The Handbook of Conflict Resolution: Theory and Practice. San Francisco: Jossey-Bass.

${ }^{5}$ As quoted at http://www.reinventingorganizations.com/uploads/2/1/9/8/21988088/140305_laloux_ reinventing_organizations.pdf
} 
A corporate culture and leadership model that promote formalisation of policies and procedures, specialisation and hierarchical decision-making were well suited to the demands of a manufacturing economy. It allowed executives to understand the (fairly predictable) business environment and make decisions based on information that was not necessarily important to lower level employees, to whom clearly delineated functions within the organisation were assigned.

Today, however, businesses operate in an environment characterised by turbulence, uncertainty and rapid technological, social and political change unlike anything we have experienced before and in which the old models are becoming obsolete (Bennett and Lemoine 2014). This new environment is often referred to as a "VUCA"6 environment, a term first applied to military strategy after the end of the Cold War but that has become a trendy managerial acronym for Volatility, Uncertainty, Complexity, and Ambiguity. The result is flux, instability, paralysis (due to information overload), doubt, dualities, distrust and increased levels of unresolved conflict. The VUCA environment affects not only business but all levels of society and its institutions. In this environment, "traditional" leadership styles fail to deliver the innovation and entrepreneurship that is required to remain competitive. ${ }^{7}$

\section{The Antidote: "Agile" Leadership}

The greatest danger in times of turbulence is not the turbulence. It is to act with yesterday's logic. ${ }^{8}$

The antidote to the turbulence is leadership characterised by agility (or "adaptiveness," the ability to make rapid adaptations in response to changing circumstances), creativity, improved decision-making ability through collaboration and trustworthiness (Johansen 2012). ${ }^{9}$

\footnotetext{
${ }^{6}$ The term "VUCA" originated with the United States Army War College to describe conditions resulting from the end of the Cold War. The VUCA concept has since been adopted throughout businesses and organisations in many industries and sectors to guide leadership and strategy planning.

${ }^{7}$ A lot has been written on this topic. See, e.g., Sankman (2013). Nice Companies Finish First Why Cut-Throat Management Is Out and Collaboration Is In. Palgrave London: St Martin's Press; Grant (2013). Give and Take: A Revolutionary Approach to Success. New York: Viking Press; Hansen (2009). How Leaders Avoid the Traps, Build Common Ground, and Reap Big Results. Boston: Harvard Business Review Press; Morgan (2012). The Collaborative Organization: A Strategic Guide to Solving Your Internal Business Challenges Using Emerging Social and Collaborative Tools. New York: Mc GrawHill. See also Hamel (2001). First, let's fire all the managers. HBR (available at https://hbr.org/2011/12/first-lets-fire-all-the-managers (last accessed 26 March 2017). ${ }^{8}$ Attributed to Peter Drucker (http://www.azquotes.com/quote/521436, last accessed 28 April 2017). ${ }^{9}$ This is reminiscent of what has been described as "Situational Leadership" in accordance with the model first developed by Hersey and Blanchard would probably be appropriate. See Hersey and Blanchard (1977). Management of Organizational Behavior: Utilizing Human Resources. New Jersey/Prentice Hall. See also Goleman (2000). "Leadership that gets results." HBR, March-April
} 
Such leaders, it has been noted, are not driven by ego and a desire for control, but tend to possess a blend of humility, confidence and assertiveness (Botelho et al. 2017). Their humility means that they don't believe they have all the answers: in their decision-making they consciously seek information, suggestions and views from relevant others in the organisation, irrespective of their hierarchical position. Their confidence and assertiveness means they are not only inclusive but are also able to arrive at decisions and implement them. It is the ability to take charge, engage the wisdom and insights of others and then to make fast decisions on the basis of the inputs received. ${ }^{10}$ They also focus strongly on employee development and providing those they lead with positivity and a future orientation (Gallup 2017). While they give everyone a "voice," not everyone has a "vote." A collaborative culture, in other words, does not imply that organisations must succumb to potentially debilitating consensus-driven decision-making (Botelho et al. 2017).

Yet organisations face a mismatch: while today's organisations require leaders who are trustworthy, respectful and inclusive, who can subordinate their own ego and agenda and give up power and resources for the greater organisational good, many organisations are still run by operational leaders who are competent at what they do yet have a mindset or mental model that dictates that to be effective, they need hierarchical power and direct control over a specific set of resources which they can deploy to achieve results (Botelho et al. 2017).

Organisations that are structured and operate in this manner inhibit the kind of "agile" leadership required to meet the challenges of the current environment (Lash 2012). ${ }^{11}$ As a 2017 Gallup Global Workplace Report demonstrates, one key consequence of this is employee disengagement: by denying employees the opportunity to gravitate towards roles and responsibilities that play to their inherent abilities, a culture of command and control tends to stifle employee motivation and entrepreneurship. $^{12}$

While a change in this competitive mental model is key to developing the kind of agile leadership organisations need today, this is not an easy task, largely because of how we are seemingly "hard-wired."

issue, 78-90. In essence, situational leadership posits that there is no single "best" style of leadership. Effective leadership is task-relevant, and the most successful leaders are those who adapt their leadership style to the ability and willingness of the individual or group they are attempting to lead or influence. Effective leadership varies, not only with the person or group that is being influenced, but it also depends on the task, job or function that needs to be accomplished.

${ }^{10}$ Interview with Prof John Latham, Monfort Institute on "The collaborative leader," published 10/01/2010, available at https://www.youtube.com/watch? $\mathrm{v}=$ QowFJswk_ZA (last accessed 3 February 2018).

${ }^{11}$ See also Yukl and Mahsud (2010). "Why flexible and adaptive leadership is essential." Consulting Psychology Journal: Practice and Research, 62(2): 81-93.

${ }^{12}$ The report suggests that, globally, the level of engagement is possibly as low as $15 \%$. 


\title{
4 A Bridge Too Far?
}

The challenge today, as Nicholson surmises (Nicholson 2003), is how to reconcile the demands of the information age with, what he refers to as "stone age minds"? It has been said that as a species, we are not programmed to compromise. We have an innate aggression that programmes us to win-and in winning we want to see others lose (Randolph 2010).

In his reflections on this "win-lose mindset" that still characterises leadership in many organisations, Finkelstein (2003) identified what he refers to as the "seven habits of unsuccessful leaders." 13 These include their belief that they have all the answers; the fact that they ruthlessly eliminate anyone who isn't completely behind them; their under-estimation of the obstacles their organisations face; and their stubborn reliance on what worked for them in the past. After recalling a number of major corporate failures presided over by such leaders, he only half-jokingly states (Finkelstein 2003, p. 73)

\begin{abstract}
What's remarkable is that the individuals who possess the personal qualities that make this magnitude of destruction possible usually possess other, genuinely admirable qualities. It makes sense: Hardly anyone gets a chance to destroy so much value without demonstrating the potential for creating it. Most of the great destroyers of value are people of unusual intelligence and talent who display personal magnetism. ... What's the secret of their destructive powers? I found that spectacularly unsuccessful people had seven characteristics in common. Nearly all of the leaders who preside over major business failures exhibit four or five of these habits. The truly gifted ones exhibit all seven. But here's what's really remarkable: Each of these seven habits represents a quality that is widely admired in the business world. Business not only tolerates the qualities that make these leaders spectacularly unsuccessful, it celebrates them.
\end{abstract}

One of our biggest distinctions as a species, however, is our unique capacity to make counter-evolutionary choices (Diamond 1997). This includes the ability to adapt our mental models or mindset ${ }^{14}$ and in consequence of that also adapt our strategies and behaviours when, e.g., negotiating change, making decisions, or dealing with differences. ${ }^{15}$

Yet even with the right mindset, perhaps the biggest obstacle leaders will face in their quest to instil a collaborative culture is to gain and maintain the trust of those they lead.

\footnotetext{
${ }^{13}$ A play on Steven Covey's popular 1989 book, The 7 Habits of Highly Effective People. New York: Free Press.

${ }^{14}$ The general attitudes and the way they typically think about things-Collins Dictionary available at https://www.collinsdictionary.com/dictionary/english/mindset (last accessed 13 February 2017).

${ }^{15}$ Mindsets or mental models affect what we do and how we do it: Pfeffer (2005) "Changing mental models: HR's most important task." Human Resource Management 123-128; Van Boven and Thompson (2003). "A Look into the Mind of the Negotiator: Mental Models in Negotiation." Group Processes \& Intergroup Relations. 6(4) 387-404.
} 


\section{Gaining Trust and Instilling a Collaborative Culture in Organisations}

Although research has identified many determinants of cooperation, virtually all scholars have agreed that one especially immediate antecedent is trust (Smith et al. 1995).

Trust is associated with enhanced collaboration, information sharing and problem-solving (Lewicki and Tomlinson 2003; Hurley 2006).

\subsection{What Is "Trust"?}

The phenomenon of trust has been extensively explored by scholars from a variety of disciplines across the social sciences, including economics, workplace relations, social psychology and political science.

Trust has been defined in various ways. Mayer et al. (1995) define it as "the willingness of a party (the "trustor") to be vulnerable to the actions of another party based on the expectation that the other will perform a particular action important to the trustor, irrespective of the ability to monitor or control that other party."16

The ability to build trust has become a key organisational competence, particularly as more and more responsibilities are devolved to teams and individuals in the pursuit of greater organisational agility (Lewicki et al. 1998). ${ }^{17}$ Peterson and Kaplan (2016) refers to it as the main leadership competency needed today, primarily because it affects every other competency leaders need to have. The weight of evidence also suggests that trust in people outside one's own family or social group is strongly positively related to economic growth (World Development Report 2015).

Trust is essential for organisations to function properly (Hardin 2002). Deutsch (1962) refers to trust as the prerequisite for collaboration within an organisation. ${ }^{18}$ Trusting relationships also enhance the quality of an employee's work life: when

\footnotetext{
${ }^{16}$ Many other definitions of trust exist. See, generally, Fulmer and Gelfand. "At What Level (and in Whom) We Trust: Trust Across Multiple Organizational Levels." Journal of Management 38 (4):1167-1230. Lewicki and Tomlinson (2003). "Trust and trust building" (available at http:// www.beyondintractability.org/essay/trust-building) define trust as "a generalized expectancy that other people can be relied on." However, most definitions recognise the core ingredients of interpersonal trust, i.e., benevolence, integrity and competence. Some also add reliability.

${ }^{17}$ See also Kim and Mauborgne (2003). "Fair process: managing in the knowledge economy." Harvard Business Review, 127-136 who state: "When employees don't trust managers to make good decisions or to behave with integrity, their motivation is seriously compromised. Their distrust and its attendant lack of engagement is a huge, unrecognized problem in most organizations."

${ }^{18}$ But see Mayer et al. (1995) "An integrative model of organizational trust." Academy of Management Review. 20(3) 709-734 at 712: "Although trust can frequently lead to cooperative behavior, trust is not a necessary condition for cooperation to occur, because cooperation does not necessarily put a party at risk." In other words, cooperation may also stem from other motives, e.g., fear of punishment.
} 
trust is relatively high, employees are more committed to the organisation and their work (Hardin 2002). ${ }^{19}$

\subsection{The Trust Deficit}

Hurley (2006, p. 55) found that roughly half of all managers don't trust their leaders:

That's what I found when I recently surveyed 450 executives of 30 companies from around the world. Results from a Golin Harris survey of Americans back in 2002 were similarly bleak: $69 \%$ of respondents agreed with the statement 'I just don't know who to trust anymore'. In that same year the University of Chicago surveyed 800 Americans and discovered that more than four out of five had 'only some' or 'hardly any' confidence in the people running major corporations. Granted, trusting corporate leaders in the abstract is different from trusting your own CEO, and some companies and executives are almost universally considered trustworthy; but the general trend is troubling.

Enron, the bank crisis of a almost decade ago, Volkswagen's VW emissions fiasco and other recent corporate scandals underscore just how costly and damaging a breach of trust can be.

There is a saying — apparently of Dutch origin — that goes: "Trust arrives on foot but leaves on horseback." Damaged or broken trust can leave a permanent scar not only on a company's reputation but on employees' levels of motivation and performance as well (Lewicki and Tomlinson 2003; Lewicki et al. 1998). Factors that have been found to cause a breakdown in trust include disrespectful behaviours, poor communication, broken promises, ineffective leadership, not taking responsibility for mistakes, and incongruence, or inconsistency between word and deed (Lewicki et al. 2016).

Can broken trust be repaired? Recent research indicates that this is possible, although it is not as straightforward as building trust in the first place (Lewicki et al. 2016). At the very least, the victim must be prepared to reconcile. The victim has to

\footnotetext{
${ }^{19}$ Zak (2017). "The Neuroscience of Trust," $H B R$, January-February reports on the results of a US survey conducted to determine levels of trust in a number of organisations, using certain indicators: "The effect of trust on self-reported work performance was powerful. Respondents whose companies were in the top quartile indicated they had $106 \%$ more energy and were $76 \%$ more engaged at work than respondents whose firms were in the bottom quartile. They also reported being $50 \%$ more productive-which is consistent with our objective measures of productivity from studies we have done with employees at work. Trust had a major impact on employee loyalty as well: Compared with employees at low-trust companies, 50\% more of those working at high-trust organizations planned to stay with their employer over the next year, and $88 \%$ more said they would recommend their company to family and friends as a place to work. My team also found that those working in high-trust companies enjoyed their jobs $60 \%$ more, were $70 \%$ more aligned with their companies' purpose, and felt $66 \%$ closer to their colleagues. And a high-trust culture improves how people treat one another and themselves. Compared with employees at low-trust organizations, the high-trust folks had $11 \%$ more empathy for their workmates, depersonalized them $41 \%$ less often, and experienced $40 \%$ less burnout from their work. They felt a greater sense of accomplishment, as well-41\% more."
} 
be given reason to believe that the violator will make efforts at righting the wrongs and tale steps to minimise future violations (Lewicki and Tomlinson 2003). In the absence of this, the victim has no incentive to attempt reconciliation and restore trust.

The lessons for leaders should be obvious: while the task of establishing trust is in itself a difficult challenge, changing a culture of distrust caused by past violations will require a very conscious and sustained effort to win back the confidence of employees.

\subsection{Trustworthiness: The Basis of Trust}

Our trust in others is grounded in our evaluation of that person's trustworthiness, that is: their abilities, integrity and benevolence (Hardin 2002). ${ }^{20}$ Ability refers to an assessment of the other's knowledge, skill, or competency. We need some sense that the other is able to perform in a manner that meets our expectations (Lewicki and Tomlinson 2003). Integrity is the degree to which we perceive that the other person adheres to principles and norms that are acceptable to us. Benevolence is our assessment that the other person is concerned enough about our welfare to either advance our interests, or at least not impede them.

Ability and integrity are likely to be most influential early in a relationship, as information on one's benevolence needs more time to emerge. The effect of benevolence will increase as the relationship between the parties grows closer (Lewicki and Tomlinson 2003). As perceived trustworthiness increases, trust will also increase (Hardin 2002).

\subsection{Building Trust}

Trust building is a two-way process. It requires mutual commitment and effort. To build their own trustworthiness, however, leaders therefore should perform competently (certainly functionally but ideally also in terms of so-called "soft skills"); be consistent and predictable; and show concern for others (empathy).

A key vehicle for establishing trustworthiness is what has been referred to as "procedural justice," or what Purcell (2012) refers to as "voice." ${ }^{21}$ Purcell (2012), for

\footnotetext{
${ }^{20}$ Peterson with Kaplan (2016). The 10 laws of trust. New York: Amacom mention character, competence and authority as the key components. See further Mayer et al. (1995) "An inegrative model of organizational trust." Academy of Management Review. 20(3): 709-734.

${ }^{21}$ See also Lewicki and Tomlinson (2003). "Trust and trust building" available at https://www. beyondintractability.org/essay/trust_building (last accessed 4 February 2018) and Lash (2012). "The Collaboration Imperative." Ivey Business Journal, January/February issue, available at http:// iveybusinessjournal.com/publication/the-collaboration-imperative/ (last accessed 2 February 2018).
} 
example, observed how giving employees voice is intimately connected to the generation of trust in the work environment.

Kim and Mauborgne (2003, p. 8) confirm the vital role that voice-or procedural justice-plays in the trust-building process:

The psychology of fair process, or procedural justice, is quite different. Fair process builds trust and commitment, trust and commitment produce voluntary co-operation, and voluntary cooperation drives performance, leading people to go beyond the call of duty by sharing their knowledge and applying their creativity. In all the management contexts we've studied, whatever the task, we have consistently observed this dynamic at work.

If people are not encouraged to contribute their ideas, e.g., because of a lack of trust or fear of negative consequences if and when they do, they will remain silent and thus contribute to decision-making on the basis of incomplete data. On the other hand, allowing an unfettered exchange of insights and ideas can help leaders build a comprehensive understanding of the business environment and generate appropriate adaptations and innovative solutions to challenges that arise (Kenney 2010).

\subsection{Collaboration}

Collaboration involves people working together to create something that no individual can create and do single-handedly. It is about positively and actively wanting and acting in unity with others to achieve a common goal (McDermott and Hal 2016).

In a collaborative environment, the leader's role is to set the vision and guide people to interact in ways that tap into, and leverage, individual strengths to create collective outcomes. Leadership is focused on guiding and facilitating outcomes-rather than directing them - and safeguarding the collaborative process. It is more about leading the process, not the people. It is about making connections between the right people, bridging diverse cultures and getting members used to sharing ideas, resources and power across hierarchies and silos (Reeves and Deimler 2011).

Collaboration works best when the roles of individual team members are clearly defined and well understood and they are then given space to do a significant portion of their work independently. Without such clarity, team members are likely to waste too much energy negotiating roles or protecting turf, rather than focus on the task at hand (Gratton and Erickson 2007). 


\subsection{Why Instil a Culture of Collaboration?}

Collaboration has a number of advantages for organisations:

- If they are part of the process of decision-making, members of a collaborative group are more likely to be willing to buy into and take responsibility for implementing the group's action plan (Kim and Mauborgne 2003).

- Because it is an open process that encourages discussion and dialogue, collaboration builds trust among those involved in the process (Kim and Mauborgne 2003).

- Collaboration can help to "de-silo" organisational thinking and behaviour by open dialogue between different parts of the organisation across functional domains (Reeves and Deimler 2011).

- People possess information that can only be accessed with their consent and active cooperation (Kim and Mauborgne 2003). Collaboration provides access to such information and ideas and thus improves the quality of decision-making: solutions arrived at are likely to be better than those developed in a vacuum, or by only a small number of people (Kuhl et al. 2005).

- A collaborative culture leads to a different way of dealing with people-related problems, including internal conflicts (Reeves and Deimler 2011).

For all its advantages, there are potential disadvantages that go with collaborative leadership as well (Lash 2012): it can be frustrating, slow and time consuming. There is a danger of "collaborative overload" if left unguided (Cross et al. 2016). There's also no guarantee that it will work with a particular group.

Trying to instil a collaborative culture might also face tough resistance: many people in organisations would prefer a leader to tell them exactly what they need to do. Being asked to share leadership might cause resentment and leave them feeling uncertain (Cross et al. 2016).

Finally, collaboration demands that leaders subordinate their egos: they are not the boss and may have to forego any credit if the group is successful (Lash 2012).

\subsection{Profile of a "Collaborative" Leader ${ }^{22}$}

If you bring the appropriate people together in constructive ways with good information, they will create authentic visions and strategies for addressing the shared concerns of the organization (sic) or community (Chrislip and Larson 1994, p. 89)

"Collaborative leaders" are not necessarily found in the top hierarchy of organisations. They may be external consultants, non-executive board members or team leaders (Reeves and Deimler 2011).

\footnotetext{
${ }^{22}$ The term is not used here to describe a new type of leadership but rather the characteristics of leaders who are able to instil a collaborative culture.
} 
They are trusted and respected by the groups and individuals they have to deal with because they have a solid reputation for trustworthiness, i.e., they have competence, consistency and integrity. "Collaborative leaders" tend to have good facilitation skills and have a tolerance for and understanding of how to manage conflict. They are good listeners yet are also assertive and persuasive (Reeves and Deimler 2011).

"Collaborative leaders" are able to create the conditions and processes that would maximise synergies between people. The emphasis is less on producing a solution to a known problem and more on developing new ways to reframe situations and develop unanticipated combinations of actions (McDermott and Hal 2016).

The key to instilling a sustainable culture of trust and collaboration lies in adopting an appropriate mental model (Hill and Levenhagen 1995; Lewis et al. 2014).

\section{Changing Mindsets}

We don't see things as they are; we see them as we are (Nin 1993).

The frames our minds create define-and confine — what we perceive to be possible. Every problem, every dilemma, every dead end we find ourselves facing in life, only appears unsolvable inside a particular frame or point of view (Zander and Zander 2000).

\subsection{Mental Models ${ }^{23}$}

Senge (1990) ${ }^{24}$ defines it as "deeply ingrained assumptions, generalizations, or even pictures and images that influence how we understand the world and how we take action." For Van Boven and Thompson (2003, p. 388) mental models are:

\footnotetext{
${ }^{23}$ There is an ongoing debate over where in the brain mental models are located, i.e. in the long or short-term memory. There are also different types of mental models, i.e., individual, team and shared mental models: "A shared mental model is the mental model constructed and shared when individuals interact together in a team setting, it represents the shared cognition among groups of individuals. A team model is the collective task and team relevant knowledge that team members bring to a situation. The team's collective and dynamic understanding that they bring to a specific situation is referred to as a team situation model." See Jones et al. (2011). "Mental models: an interdisciplinary synthesis of theory and methods." Ecology \& Society 16(1): 46. Available at http://www.ecologyandsociety.org/vol16/iss1/art46/ (last accessed 28 April 2017).

${ }^{24}$ Senge also defines learning organisations as $(1990$, p. 3) “. . . organizations where people continually expand their capacity to create the results they truly desire, where new and expansive patterns of thinking are nurtured, where collective aspiration is set free, and where people are continually learning to see the whole together."
} 
cognitive representations of the causal relationships within a system that allow people to understand, predict, and solve problems within that system. Mental models are based on people's experiences and expectations. They can guide behaviour in different situations, organise thoughts about a problem, and influence the interpretation of information.

Mental models affect our thinking and help us make sense of our world (Van Boven and Thompson 2003, p. 388). ${ }^{25}$ They are simplified internal representations of reality that allows us to interact with the world. They enable thought and action, but also constrain them. They form the basis of reasoning, decision making, and behaviour. Without mental models of the world, decision-making would be difficult, if not impossible (World Development Report 2015). Without shared mental models, it would be impossible in many cases for people to solve collective action problems, create institutions, feel a sense of belonging and solidarity, or even understand one another (World Development Report 2015).

\subsection{Changing Mindsets}

Everything can be taken from a man but one thing: the last of the human freedoms- to choose one's attitude in any given set of circumstances, to choose one's own way (Frankl 1959, p. 86).

We have the power to choose the assumptions we make. Each choice has consequences for how we feel and what we do, the decisions we make, and how we act in the situations we confront in seeking to make organisations more effective and successful (Pfeffer 2005).

Mental models affect where we direct our attention and what information we rely on (Van Boven and Thompson 2003). If they are out of sync with reality they may substantially limit the type and amount of information decision makers use, greatly affecting decision outcomes. This is because we may ignore information that violates our current assumptions and automatically fill in missing information based on what our mental models suggest is likely to be true. Mental models enable thought and action, yet also constrain them. Mental models have to be highly dynamic to adapt to continually changing circumstances and to evolve over time through learning (Van Boven and Thompson 2003), yet abandoning established mental models and adopting different ones can be very difficult. ${ }^{26}$ As Koestler (1972, p. 235) states:

\footnotetext{
${ }^{25}$ See also "Thinking with mental models" (2015) World Development Report, World Bank available at http://pubdocs.worldbank.org/en/504271482349886430/Chapter-3.pdf (last accessed 18 February 2017).

${ }^{26}$ The authors of the World Bank report, above, provide this example of the power of mental models and the difficulty of changing them:
}

"The power and persistence of mental models are strikingly captured by a story Nelson Mandela told of a time when he flew from Sudan to Ethiopia. He started to worry when he noticed that the pilot was black: 
Of all forms of mental activity, the most difficult to induce ... is the art of handling the same bundle of data as before, by placing them in a new system of relations with one another by giving them a different framework, all of which virtually means putting on a different kind of thinking-cap for the moment. It is easy to teach anybody a new fact ... but it needs light from heaven above to enable a teacher to break the old framework in which the student is accustomed to seeing.

Policy interventions may be able to trigger a change in mental models, but may also have the opposite effect. It has been found, for example, that only under certain circumstances will affirmative action policies lead to a positive change in attitudes: "If negative stereotypes shape perceptions strongly enough, interaction may simply reinforce the negative stereotypes, undermining the hoped-for effects of the policy" (World Development Report 2015).

The formation of a mental model in a person's mind is the result of both biology, i.e., an ability inherent to the human mind, and learning (Jones et al. 2011). The discipline starts with self-reflection, learning to discover our own internal pictures of the world, and then to bring them to the surface and scrutinise them rigourously. It also includes the ability to carry on what Senge (1990) calls "learningful conversations" where people expose their own thinking effectively and make that thinking open to the influence of others.

Results from a 2015 survey conducted by McKinsey \& Company found that the most effective initiatives to change mindsets and behaviours are: role modelling; fostering understanding and conviction; reinforcing changes through formal mechanisms; and developing talent and skills.

The process of how initiatives are designed is critical too: involving input from a range of company stakeholders is more likely to lead to successful transformations:

People must be exposed to their implicit mental models and examine them before we can change them. Changing what people do is easier than changing what they think since mindsets and assumptions are often deeply embedded beyond conscious thought. Yet changing the way people think about situations is, in fact, the most powerful and useful way to ultimately change behaviour and thereby affect organisational results (Pfeffer 2005, p. 125)

\subsection{Embedding a New Mindset}

Developing a new collaborative mental model alone is not enough, however. Institutions and mental models are closely related and sometimes a change in a

'We put down briefly in Khartoum, where we changed to an Ethiopian Airways flight to Addis. Here I experienced a rather strange sensation. As I was boarding the plane I saw that the pilot was black. I had never seen a black pilot before, and the instant I did I had to quell my panic. How could a black man fly an airplane?"”

See also Reger et al. (1994). "Creating earthquakes to change organizational mindsets," Academy of Management Executive 8(4): 31-43. 
mental model also requires institutional change. Barker (1989) suggests that when adopting a new paradigm, all aspects of the system must change in accordance with the new paradigm. Paradigm shifting, therefore, does not become fully operable until all parts of the system are changed and aligned with the new paradigm.

Furthermore, if leaders and their organisations are to develop a different mental model to facilitate a collaborative, high trust environment, it will be necessary for people to go beyond merely learning new skills: it requires the development of new orientations, a change in corporate culture, vision and values. Moving the organisation in the right direction also entails working to transcend the sorts of internal politics and game playing that dominate traditional organisations. It means fostering openness and seeking to distribute business responsibly far more widely while retaining coordination and control (Quinn 2004).

\section{Conclusion}

When we commit to a vision to do something that has never been done before, there is no way to know how to get there. We simply have to build the bridge as we walk on it (Quinn 2004).

For businesses to survive and thrive in the so-called "VUCA" world, an organisational culture that fosters trust and collaboration is called for. At corporate level this will open up new paths to growth, while allowing for more autonomy for and engagement of individuals. But collaboration is more than just a matter of process or skills. For it to be sustainable, it has to be supported by a fundamental change in the traditional, competitive mental models so often found among leaders and inside organisations. This, in return, requires that issues of trust, culture and values within organisations are also addressed.

Sustained change needs a shift in mindset away from competing to survive to collaborating to win; from silo mentalities to openness; from making decisions in small, elite circles to allowing employees a meaningful "voice" in decision that affect them, including the creation of an environment that encourages their inputs and critique, from seeing conflict as bad to embracing it as a potential resource; from behaviours that destroy trust or prevent its development, to the active pursuit of behaviours that develop trust. 


\section{Bibliography}

Archer D, Cameron A (2009) Collaborative leadership: building relationships, handling conflict and sharing control. Routledge, New York

Barker J (1989) Discovering the future: the business of paradigms. Infinity Limited Incorporated, St. Paul

Bennett N, Lemoine GJ (2014) What VUCA really means for you. HBR, Available https://hbr.org/ 2014/01/what-vuca-really-means-for-you. Accessed Feb 2017

Botelho EL, Powell RK, Kincaid S, Wang D (2017) What sets successful CEOs apart. HBR, May-June issue, 70-77

Chrislip D, Larson CE (1994) Collaborative leadership: how citizens and civic leaders can make a difference. Jossey-Bass, Boston

Cross R, Rebele R, Grant A (2016) Collaborative overload. HBR, January-February issue

Deutsch M (1962) Cooperation and trust: some theoretical notes. In: Marshall RJ (ed) Nebraska symposium on motivation. University of Nebraska Press, Lincoln, pp 275-319

Diamond J (1997) Why is sex fun? The evolution of human sexuality. Basic Books, New York

Doz Y, Kosonen M (2008) The dynamics of strategic agility: Nokia's rollercoaster experience. Calif Manag Rev 50(3):95-118

Finkelstein S (2003) Why smart executives fail. Penguin, London

Fisher R, Ury W, Patton B (2012) Getting to yes: negotiating an agreement without giving in. Random House Business Books, London

Forrester JW (1971) Counterintuitive behavior of social systems. Technol Forecast Soc Chang $3: 1-22$

Frankl V (1959) Man's search for meaning. Beacon Press, Boston

Fulmer CA, Gelfand MJ (2012) At what level (and in whom) we trust: trust across multiple organizational levels. J Manag 38(4):1167-1230

Gallup (2017) State of the global workplace report. Available http://www.gallup.com/services/ 178517/state-global-workplace.aspx. Accessed 3 Feb 2018

Goleman D (2000) Leadership that gets results. HBR, March-April issue, 78-90

Grant A (2013) Give and take: a revolutionary approach to success. Viking Press, New York

Gratton L, Erickson TJ (2007) Eight ways to build collaborative teams. HBR, Available https://hbr. org/2007/11/eight-ways-to-build-collaborative-teams. Accessed March 2016

Hamel G (2001) First, let's fire all the managers. HBR, Available https://hbr.org/2011/12/first-letsfire-all-the-managers. Accessed March 2017

Hansen M (2009) How leaders avoid the traps, build common ground, and reap big results. Harvard Business Review Press, Boston

Hardin R (2002) Trust and trustworthiness. Russel Sage Foundation, New York

Hersey P, Blanchard KH (1977) Management of organizational behavior: utilizing human resources. Prentice Hall, New Jersey

Hill RC, Levenhagen M (1995) Metaphors and mental models: sensemaking and sensegiving in innovative and entrepreneurial activities. J Manag 21(6):1057-1074

Hurley RF (2006) The decision to trust. HBR, September, 55-62

Ibarra H, Hansen MT (2011) Are you a collaborative leader? HBR, Available https://hbr.org/2011/ 07/are-you-a-collaborative-leader. Accessed April 2017

Johansen B (2012) Leaders make the future: ten new leadership skills for an uncertain world. Berret-Koehler, San Francisco

Jones NA, Ross H, Lynam T, Perez P, Leitch A (2011) Mental models: an interdisciplinary synthesis of theory and methods. Ecol Soc 16(1):46. Available http://www.ecologyandsociety.org/vol16/ iss1/art46/. Accessed 28 April 2017

Kenney S (2010) Creating adaptive organizations, American management association. Available http:// www.amanet.org/training/articles/creating-adaptive-organizations.aspx. Accessed Aug 2017

Kim WC, Mauborgne R (2003) Fair process: managing in the knowledge economy. Harv Bus Rev, January issue, 127-136 
Koestler A (1972) The roots of coincidence. Vintage Books, New York

Kuhl S, Schnelle T, Tillmann F-J (2005) Lateral leadership: an organizational approach to change. J Chang Manag 5(2):177-189

Laloux F (2014) Reinventing organizations. Nelson Parker, Brussels

Lash R (2012) The collaboration imperative. Ivey Bus J, January/February. Available http:// iveybusinessjournal.com/publication/the-collaboration-imperative/. Accessed Feb 2017

Lewicki RJ, Tomlinson EC (2003) Trust and trust building. Available http://www.beyondintractability. org/essay/trust-building. Accessed Feb 2017

Lewicki RJ, Wiethoff C (2000) Trust, trust development, and trust repair. In: Coleman P, Deutsch M, Marcus EC (eds) (2014) The handbook of conflict resolution: theory and practice. Jossey-Bass, San Francisco

Lewicki RJ, McAllister DJ, Bies RJ (1998) Trust and distrust: new relationships and realities. Acad Manag Rev 23:438-458

Lewicki R, Elgoibar P, Euwema M (2016) The tree of trust: building and repairing trust in organizations. In: Elgoibar P, Euwema M, Munduate L (eds) Building trust and constructive conflict management in organizations. Springer, Switzerland

Lewis MW, Andriopoulos C, Smith WK (2014) Paradoxical leadership to enable strategic agility. Calif Manag Rev 56(3):58-77

Mayer RC, Davis JH, Schoorman FD (1995) An inegrative model of organizational trust. Acad Manag Rev 20(3):709-734

McDermott I, Hal CM (2016) The collaborative leader. Crown House Publishing, London

McKinsey \& Company (2015) The science of organisational transformations. Available http://www. mckinsey.com/business-functions/organization/our-insights/the-science-of-organizational-transfor mations. Accessed 18 Feb 2018

Morgan J (2012) The collaborative organization: a strategic guide to solving your internal business challenges using emerging social and collaborative tools. McGraw-Hill, New York

Nicholson N (2003) Managing the human animal. Texere Publishing, Florence

Nin A (1993) Seduction of the minotaur. Penguin Books, London

Paul J. Zak (2017) The Neuroscience of Trust, HBR, January-February.

Peterson J, Kaplan DA (2016) The 10 laws of trust. Amacom, New York, p XII

Pfeffer J (2005) Changing mental models: HR's most important task. Hum Resour Manag:123-128

Purcell J (2012) ACAS future of workplace relations. Discussion paper series. Available http:// www.acas.org.uk/media/pdf/g/7/Voice_and_Participation_in_the_Modern_Workplace_chal lenges_and_prospects.pdf. Accessed Feb 2017

Quinn RE (2004) Building the bridge as you walk on it: a guide for leading change. Jossey-Bass, San Francisco

Randolph P (2010) Compulsory mediation? Blog piece. Available at https://www.newlawjournal. co.uk/content/litigation-v-mediation. Accessed 13 Feb 2018

Reed M (2001) Organization, trust and control: a realist analysis. Organ Stud:201-228

Reeves M, Deimler M (2011) Adaptability: the new competitive advantage. Harv Bus Rev:1-15

Rigby DK, Sutherland J, Takeuchi H (2016) Embracing agile. HBR, Available https://hbr.org/2016/ 05/embracing-agile. Accessed March 2017

Sankman P (2013) Nice companies finish first: why cut-throat management is out and collaboration is in. St Martin's Press, New York

Senge P (1990) The fifth discipline: the art and practice of the learning organization. Doubleday, New York

Smith KG, Carroll SJ, Ashford SJ (1995) Intra- and interorganizational cooperation: toward a research agenda. Acad Manag J 38(1):7-23

Van Boven L, Thompson L (2003) A look into the mind of the negotiator: mental models in negotiation. Group Process Intergroup Relat 6(4):387-404

World Development Report (2015) Thinking with mental models. Available http://pubdocs. worldbank.org/en/504271482349886430/Chapter-3.pdf. Accessed 18 Feb 2017 
Yukl G, Mahsud R (2010) Why flexible and adaptive leadership is essential. Consult Psychol J: Pract Res 62(2):81-93

Zander RS, Zander B (2000) The art of possibility. Harvard Business School Press, Boston

Barney Jordaan holds a doctorate in law from Stellenbosch University, South Africa. He is currently professor of management practice (negotiation and dispute resolution) at Vlerick Business School, Belgium. Jordaan is also an Extraordinary Professor at the University of Stellenbosch Business School. Prior to moving to Belgium in 2014 he held a number of academic appointments in South Africa. These included 14 years as professor of law at Stellenbosch University and thereafter as professor of negotiation and conflict management at the University of Stellenbosch Business School and the Graduate School of Business, University of Cape Town. In conjunction with his academic involvement, Barney also practised as human rights lawyer in South Africa during the apartheid era before co-founding a consulting firm in 1998 which advises corporate clients on conflict management strategies, negotiation and related matters. He has been involved in the mediation field since 1989 as practising mediator, trainer and coach. He is an internationally certified as mediator with, amongst others, the Centre for Effective Dispute Resolution (CEDR, UK) and the International Mediation Institute in The Hague.

Open Access This chapter is licensed under the terms of the Creative Commons Attribution 4.0 International License (http://creativecommons.org/licenses/by/4.0/), which permits use, sharing, adaptation, distribution and reproduction in any medium or format, as long as you give appropriate credit to the original author(s) and the source, provide a link to the Creative Commons licence and indicate if changes were made.

The images or other third party material in this chapter are included in the chapter's Creative Commons licence, unless indicated otherwise in a credit line to the material. If material is not included in the chapter's Creative Commons licence and your intended use is not permitted by statutory regulation or exceeds the permitted use, you will need to obtain permission directly from the copyright holder.

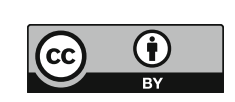

